\title{
THE
}

\section{Do Weather Fluctuations Cause People to Seek Information about Climate Change?}

Corey Lang

University of Rhode Island, clang@uri.edu

Follow this and additional works at: https://digitalcommons.uri.edu/enre_facpubs

Part of the Agricultural and Resource Economics Commons, and the Econometrics Commons

The University of Rhode Island Faculty have made this article openly available. Please let us know how Open Access to this research benefits you.

This is a pre-publication author manuscript of the final, published article.

Terms of Use

This article is made available under the terms and conditions applicable towards Open Access Policy Articles, as set forth in our Terms of Use.

\section{Citation/Publisher Attribution}

This is a pre-print of an article published in Climatic Change. The definitive publisher-authenticated version is available online here.

This Article is brought to you for free and open access by the Environmental and Natural Resource Economics at DigitalCommons@URI. It has been accepted for inclusion in Environmental and Natural Resource Economics Faculty Publications by an authorized administrator of DigitalCommons@URI. For more information, please contact digitalcommons-group@uri.edu. 


\title{
Do Weather Fluctuations Cause People to SeEk Information ABout Climate Change?
}

\author{
Corey Lang* \\ Department of Environmental and Natural Resource Economics \\ University of Rhode Island
}

June 3, 2014

\begin{abstract}
Learning about the causes and consequences of climate change can be an important avenue for supporting mitigation policy and efficient adaptation. This paper uses internet search activity data, a distinctly revealed preference approach, to examine if local weather fluctuations cause people to seek information about climate change. The results suggest that weather fluctuations do have an effect on climate change related search behavior, however not always in ways that are consistent with the projected impacts of climate change. While search activity increases with extreme heat in summer and extended periods of no rainfall and declines in extreme cold in winter, search activity also increases with colder winter and spring average temperatures. Some of the surprising results are magnified when heterogeneity by political ideology and educational attainment in responsiveness is modeled, which could suggest that different people have different perceptions about what types of weather define climate change or that climate science deniers seek information through Google. However, the results also indicate that for all groups in the political and educational spectrum, there exist weather events consistent with the predicted impacts of climate change that elicit increased information seeking.
\end{abstract}

Keywords: climate change; information search; Google Trends; revealed preferences; adaptation; political bias

*214 Coastal Institute, 1 Greenhouse Rd., Kingston, RI, 02881. Email: clang@mail.uri.edu. I thank Laura Bakkensen, Carrie Gill, Sarah Jacobson, Jesse Tack, seminar participants at Clark University and the 2013 NAREA conference, and three anonymous referees for valuable comments. George Sfinarolakis and David Ryder are thanked for research assistance. This paper is a contribution of the Rhode Island Agricultural Experiment Station (\#5362). 


\section{INTRODUCTION}

Given the monumental importance of climate change, it is critical for two reasons to understand what people think about climate change and what makes them want to learn more. First, if meaningful legislation mitigating greenhouse gas emissions is to be passed, a political majority must be built. Second, given the state of the climate and current emissions patterns, regardless of what legislation is to come, some amount of adaptation will be necessary. Increased knowledge of the causes and consequences of climate change is advantageous in both cases.

To better understand information seeking behavior related to climate change, I use internet search data from Google Trends. ${ }^{1}$ Google Trends aggregates Google searches and offers a measure of relative popularity of a search term for a given time and place. Individuals use Google when they want to learn more about a topic or answer a specific question and are unsure where to look. For these reasons I see a Google search as a "revealed preference” for information seeking, active engagement and attention. These data stand in contrast with a typical survey, which is "stated preference" and passive engagement. ${ }^{2}$

Using Google Trends, this paper specifically examines if local weather fluctuations cause people to search for climate change related information. ${ }^{3}$ Essentially, as people experience anomalous weather events, do they connect those events to a larger narrative of climate change and choose to learn more?

IPCC (2013) predicts that over the $21^{\text {st }}$ century there will be increases in average temperature and extreme heat, average precipitation will increase in some places and decrease in other places, and greater frequency of droughts and floods. While the prediction for precipitation is mixed, the prediction of temperature is clear. This paper additionally explores if people respond to any weather anomalies or if unusually warm weather consistently causes search increases.

\footnotetext{
${ }^{1}$ Google Trends data are being increasingly utilized as a measure of contemporary awareness across of wide variety of indicators (e.g., Ginsberg et al. 2009 for influenza, Choi and Varian 2012 for predicting unemployment). Similar to this paper, Kahn and Kotchen (2011) use Google data to examine interest in global warming. They use state level data to show that interest in global warming declines when unemployment increases.

${ }^{2}$ Revealed preference refers to research that seeks to understand preferences by observing real choices, whereas stated preference relies on answers to questions about preferences.

${ }^{3}$ Shanahan and Good (2000) find some evidence that media attention to climate change increases during unusually warm spells.
} 
The main data I analyze are an aggregate of searches for global warming or climate change, henceforth denoted global warming + climate change. ${ }^{4}$ I also analyze search patterns for drought, flood, and weather (italics will be used throughout the paper to distinguish the specific search terms). All three additional search terms serve to validate Google Trends and the empirical methodology. In contrast to seeking information about the monumental topic of climate change, searching weather is about immediate concerns and questions like 'should I bring an umbrella?'. Drought and flood are somewhere in the middle - searchers could be interested in a single event or they could be connecting an event to something on a larger temporal or spatial scale. Because increases in the frequency and severity of droughts and floods are important, predicted impacts of climate change, these searches may also indicate adaptation potential.

I construct a panel data set of aggregate search activity for 205 media markets (essentially cities) in the Continental United States with monthly observations spanning January 2004-May 2013. After matching the Google data to local weather, I estimate a model that allows search behavior to be affected by average temperature and precipitation, as well as weather extremes (hot, cold, dry, wet) and streaks of extremes. The model also includes media market fixed effects and month-year fixed effects to ensure that identifying variation comes only from local weather fluctuations, and not climate differences, seasonal fluctuations or national events.

The results suggest that people seek information due to their personal experience, which has important implications for policy and adaptation as the effects of climate change escalate over time. Search activity increases with increases in extreme heat in summer and extended periods of no rainfall and declines in extreme cold in winter, all of which are weather fluctuations consistent with projected climate change. However, search activity also increases with decreases in average winter and spring temperatures, which are inconsistent with climate change. The results could suggest that people link weather anomalies of any kind with climate change or perhaps the engagement of deniers, who experience an unusually cool winter and go online to confirm their skeptical views.

In addition, I use this framework to examine heterogeneity by political ideology and educational attainment in the types of weather fluctuations that cause online information seeking

\footnotetext{
${ }^{4}$ The exact query was "climate change" + "global warming", which counts any search including either of the phrases "climate change" or "global warming".
} 
about climate change. The results indicate that all groups in the political and educational spectrum have weather triggers that elicit increased information seeking and are consistent with climate change. Republican and less educated areas increase search activity in response to changes in extreme temperatures consistent with climate change, whereas more Democratic and well educated areas increase search activity in response to changes in average temperatures consistent with climate change. This could indicate that different types of people experience weather differently or have different perceptions about what type of weather defines climate change.

The first contribution of this paper is to add to the strong literature that seeks to understand the effect of local weather on beliefs that temperature is changing, that climate change is real, or that a given policy is justified (Akerlof et al. 2013, Hamilton and Stampone 2013, Zaval et al. 2014). Zaval et al. (2014) determine that this relationship is driven by attribute substitution; if people are asked about climate change, they rely on the simple heuristic of recent weather to inform their opinion. However, actively seeking information through Google is entirely different than being surveyed and compelled for an opinion. Attribute substitution is unlikely to be causing my results, and thus they represent a clearer estimate of the way people connect weather with climate change.

The second contribution is to advance our understanding of how perceptions of local weather and its impact on beliefs are heterogeneous, based on political ideology, education, race, or religion (e.g., Egan and Mullin 2012). One concern about prior findings is that survey respondents may posture answers that reflect an agenda rather than their true beliefs. For example, Goebbert et al. (2012) and Howe and Leiserowitz (2013) find that those who do not believe in global warming or are conservative are significantly less likely to accurately report unusually warm weather. These authors speculate that prior opinions can affect how people experience weather, but another interpretation is that stated opinions may not reflect true knowledge/experience when there is a desired projection of beliefs. Revealed preference data, like private and anonymous internet searches, should mitigate posturing (Stephens-Davidowitz 2013). This is the first paper to estimate the effects of weather using a revealed preference approach. In contrast to previous findings, I show that cities at all points in the spectrum do have some type of weather fluctuation consistent with climate change that triggers them to seek information about climate change. 


\section{Methodology}

This section will outline the empirical method and detail specific elements of the model that are critical for understanding the identifying assumptions and broad interpretation of the results. Specific variable definitions are postponed to the following section, which discusses the data sources and construction. For each Google search term (global warming + climate change, drought, flood, and weather), I estimate the following model:

$$
\begin{aligned}
G S I_{i t} & =\sum_{k \in \text { Season }} \alpha_{k} \cdot 1(t \in k) \cdot \text { temperature }_{i t}+\sum_{k \in \text { Season }} \beta_{k} \cdot 1(t \in k) \cdot \text { precipitation }_{i t} \\
& +\sum_{m \in \text { Extreme }} \gamma_{m} \cdot m_{i t}+\sum_{n \in \text { Streak }} \delta_{n} \cdot n_{i t}+\theta_{i}+\pi_{t}+\epsilon_{i t}
\end{aligned}
$$

$G S I_{i t}$ is the Google Search Index for media market $i$ at time $t$ (at the month-year level) for a given search term. temperature $_{i t}$ is the average temperature and precipitation $_{i t}$ is the total precipitation. $\alpha$ and $\beta$ are coefficients of interest and measure the effect of temperature and precipitation on GSI. These coefficients are estimated separately for each season $k$, as temperature or precipitation may elicit different responses by time of year. Because GSI is at the month level resolution, the analysis is constrained to be at that level. However, most weather events happen at a smaller temporal scale than month, and thus may be lost in aggregate measures of temperature and precipitation. To alleviate this concern, the model includes two sets of extreme weather variables (hot, cold, dry, wet) that not only capture the likely non-linear relationship between GSI and weather, but also capture daily variation that people experience. The first set of variables, $\sum_{m \in E x t r e m e} \gamma_{m} \cdot m_{i t}$, captures the effect of extreme weather on search data. ${ }^{5}$ The second set of variables, $\sum_{n \in \text { Streak }} \delta_{n} \cdot n_{i t}$, model the effect of streaks of extreme weather. The impetus here is to determine if a string of extreme weather days, be it hot, cold, dry, or wet, have an effect beyond the same extreme weather spaced differently. Colinearity between the average and extreme/streak variables is not a problem as discussed in the Appendix.

Two sets of fixed effects are also included in the model. $\theta_{i}$ is a media market fixed effect and captures differences in search volume and climate among media markets. These fixed effects ensure that the parameters of interest are identified from within-media market variation in

\footnotetext{
${ }^{5}$ This is similar to the semi-parametric binning approach found in Deschenes et al. (2009), who study to impact of weather on birth weight.
} 
weather and not between-media market differences in climate. $\pi_{t}$ is a month-year fixed effect that captures changes in search activity at specific points in time across all media markets. This set of variables control for 1) seasonal variation in search activity and weather trends and 2) political, media, or other events of national significance. Due to the use of media market fixed effects and the orthogonality of weather fluctuations to other possible determinants of search behavior, the GSI-weather relationship is assumed causal.

In addition to estimating Equation (1) for each Google search term, I estimate a variant of Equation (1) only for global warming + climate change that seeks to uncover heterogeneity in the weather-GSI relationship by political ideology and educational attainment. To do this, I interact each of the weather terms in Equation (1) with media market Democratic vote share and the share of each media market's population with a college degree.

\section{DATA}

\subsection{Google Trends}

Google Trends allows users to obtain aggregate search activity information for single phrases or the union of multiple phrases. Google Trends reports a time series index, which I refer to as GSI, of search activity on a 0-100 scale based on the given query's share of total searches during the same time frame. An index value of 100 indicates the maximum query share observed over the time period and all other nonzero values indicate a percentage of that maximum query share. An index of zero indicates that a minimum search volume is not reached and Google will not disclose that data. Since GSI is a percent of maximum query share, results of the regression analysis of Equation (1) will be interpreted as changes in percent of GSI. For the United States, data are available at the nation level, the state level, and at the media market level. Media markets are the smallest geographic area at which Google Trends releases data and consist of several contiguous counties, which can be thought of as cities and their surrounding areas.

During June of 2013, search data were downloaded from Google Trends for all 205 media markets in the Continental United States for the time period January 2004 through the end of May 2013. Data were downloaded for the search terms weather, drought, flood, and global warming + climate change. ${ }^{6}$ Data were downloaded for each search term and each media market

\footnotetext{
${ }^{6}$ Query share is larger for global warming than climate change. As a result, the regression results for global warming are quite similar to the results for global warming + climate change. Results for climate change by itself
} 
separately, ensuring that each time series ranges 0-100, which is appropriate for the panel data/within-variation estimators. Depending on search volume and reaching the minimum search threshold, Google Trends either produces a data series in weekly or monthly increments, with weekly being high volume search terms or media markets. While the weather time series are produced in weekly frequency format for all but three media markets, the other search terms are usually only in weekly format for the larger media markets. For consistency, all series in weekly frequency were averaged to be at the monthly scale, and the unit of observation is the media market-month-year.

To some extent for weather but for a much greater extent for the other search terms, there are often a large number of consecutive zeros that begin the time series. This pattern indicates that in the early years of a data series either these search terms were less popular than they are currently or there were fewer total searches such that the minimum threshold Google set was not reached. Looking at more aggregate data, such as the entire US, query share for each key word is similar today than it was in 2004, so the latter explanation is more likely. The leading zeros pose an identification problem because weather had approximately the same variability then as it has now, so including all of those zeros will attenuate the parameter estimates in the regression models. To address this, the leading zeros of a time series were dropped up until the point at which eight out of ten of the subsequent observations are non-zero. I chose $80 \%$ (instead of $100 \%$ ) because it is not uncommon for data series to have a mixture of zeros and non-zeros. The idea is to drop the leading string of zeros but keep the zeros that are mixed with non-zero values, which show real variation. ${ }^{7}$

Summary statistics for the Google Trends data are presented in Appendix Table A1. Importantly, $96.4 \%$ of the population is represented by media markets included in the global warming + climate change sample.

are consistent as well, but there is much less statistical significance, likely due to lower search volumes and more resulting zeros. Cavanaugh et al. (2014) explore the determinants of search interest for global warming and climate change, separately, in a cross sectional setting. While determinants are similar, their results suggest that cities with more Democrats, more college educated people and more white people are more likely to search for global warming than climate change.

${ }^{7}$ The results presented in the next section are robust to small changes in the $80 \%$ mark. An alternative strategy for dealing with the zeros is to drop the first few years of data, which is when most of the zeros occur. This strategy has the advantage that it does not disproportionately drop observations from some media markets. The results are similar when using this strategy. 


\subsection{Weather data}

Daily average temperature and total precipitation at the weather station level were downloaded from NOAA NCDC Global Historical Climatology Network. Using GIS, I matched weather stations to media markets using a shapefile derived from the county to media markets crosswalk developed by Gentzkow and Shapiro (2008). Daily temperature and precipitation were then averaged across all monitors in each media market. Each of the weather variables used in the regression analysis are derived from these data. Monthly average temperature is the average across all days in a month. Monthly total precipitation is the sum over all days in a month. There are four variables capturing extreme temperature and precipitation, and each is created by simply counting the number of days in a single month that meet the condition of extreme heat (daily temperature $>85^{\circ} \mathrm{F}$ ), cold (daily temperature $<32^{\circ} \mathrm{F}$ ), precipitation (daily precipitation $>0.5$ inches), or dryness (daily precipitation $=0$ ). ${ }^{8}$ To create the streak variables, first a variable is created that has a running total of consecutive days meeting the extreme criteria that is reset to zero every time a day fails to meet the criteria. For example, if a series of daily temperatures was $80,90,90,90,80$, then this running variable would equal $0,1,2,3,0$. Then this variable is averaged by month to get an average level of “streakiness” of the weather. Summary statistics are given in Appendix Table A2

\subsection{Additional data}

The analysis additionally uses data on total population, Democratic vote share, and share with college degree. Population comes from the 2010 Decennial Census, and these data are used to weight media markets in the regression analysis. I use the 2008 presidential election results from Dave Leip’s Atlas of Presidential Elections. I calculate the percentage of votes for the Democratic candidate, discarding votes for all third party candidates. From the 2006-2010 American Community Survey, I use the proportion of the population over age 25 with a college degree as my measure of educational attainment. All of these variables are available at the county level, and I aggregate them to the media market level. Summary statistics are available in Appendix Table A2.

\footnotetext{
${ }^{8}$ An alternative to defining extremes in absolute terms is defining them in relative terms. This would allow a $90^{\circ} \mathrm{F}$ day in Phoenix to elicit a different response than a $90^{\circ} \mathrm{F}$ day in Seattle. The online appendix reports results when defining extremes based on deviations from historical, media market-specific climate. Results are similar to those using an absolute definition of extremes, likely due to the presence of media market fixed effects, which capture the fact that Phoenix has many more $90^{\circ} \mathrm{F}$ days than Seattle.
} 


\section{RESUlts}

Table 1 presents results of the effects of weather fluctuations on search behavior using Equation (1). Column 1 in Table 1 presents results for the effect of weather fluctuations on global warming + climate change GSI. The results suggest that a $1^{\circ} \mathrm{F}$ increase in average temperature leads to a $0.13 \%$ decrease in GSI in winter and a $0.19 \%$ decrease in spring, while average temperature changes in summer and fall have no statistical impact on information seeking. The difference in magnitudes and statistical significance between these four temperature coefficients demonstrates the importance of allowing the effects to differ by season. Precipitation fluctuations in any season do not impact GSI. Turning to weather extremes and streaks, the results suggest that GSI increases $0.27 \%$ with each additional day above $85^{\circ} \mathrm{F}$, but the coefficient on hot streak is negative indicating that the marginal effect of each day above $85^{\circ} \mathrm{F}$ decays with persistence of heat. Further, information seeking increases with streaks of extreme dry, but decreases with streaks of extreme cold. Results from more parsimonious models, as well as various robustness checks are presented in the Appendix. Across models, the results generally present a consistent story.

IPCC (2013) predicts the coming century will bring increases of extreme heat, decreases with extreme cold, and extended periods of no rainfall. The results indicate that weather events in line with these predicted changes increase GSI. However, search activity is also inversely related to average winter and spring temperatures. ${ }^{9}$ One possibility to explain the results is that weather anomalies of many kinds, regardless of their consistency with climate change predictions, elicit interest about climate change. Prior work measuring the effect of weather on beliefs has found that both unusually warm and cool temperatures can increase support for climate change (Hamilton and Lemcke-Stampone 2013, Zaval et al. 2014). Another possibility is heterogeneity in the type of information that people are seeking, and these different objectives may be triggered by different types of weather. Specifically, there could be the presence of both 1) people who genuinely want to learn more, who observe unusual extreme heat and extended periods of no rain and seek information about climate change, and 2) deniers, who experience an unusually cool winter and go online to confirm their skeptical views. Unfortunately, search

\footnotetext{
${ }^{9}$ These results are not due to counteracting effects of average and extreme variables. The coefficients on the average variables are similar when excluding the extreme and streak variables from the model, and the reverse is also true. See Appendix Table A4.
} 
activity is too low for skeptic-specific Google search terms, and thus this hypothesized heterogeneity cannot be tested. ${ }^{10}$ Some support for this idea comes from the Six Americas study (Maibach et al. 2009), which finds that those with the strongest acceptance of climate change (Alarmed and Concerned) and those with the strongest denial (Dismissive) are the most engaged. The second column in Table 1 presents results for the effect of weather fluctuations on flood GSI. As expected, precipitation is a strong driver of information seeking about floods. The coefficients on average precipitation indicate a one inch increase in precipitation causes GSI to increase 1.4-1.6\%, and all coefficients are statistically significant at the 1\% level. Interestingly, the coefficient on number of days of heavy precipitation is negative, implying that extreme precipitation has less of impact than the same amount of precipitation spread over two or more days. The results also suggest that higher temperatures in fall and winter increase flood GSI.

Column 3 presents results for the effect of weather fluctuations on drought GSI. All four coefficients on average temperature are positive and statistically significant, three at the 1\% level. Further, each coefficient on extreme heat and heat streak are positive and significant indicating that extreme heat increases GSI and this effect is amplified if the very hot days are consecutive. For precipitation, lower than average precipitation in summer and the number of days with zero precipitation both increase GSI; however, increases in winter precipitation also increase GSI. One may be surprised that low precipitation is not more of a determining factor for drought GSI than high temperatures. However, drought is complex and is as much about rain as it is about evaporation and soil moisture. Further, this research design reflects personal perception, and the average person may perceive drought differently than researchers expect.

The results for flood and drought GSI bolster the idea that individuals connect local weather to larger trends and use the internet to learn more. Beyond Wikipedia and news stories, Google leads searchers to floodsmart.gov, FEMA, US drought monitor, and drought.gov. In addition to more information on a local event, these websites provide individuals with future expectations and best management practices. Returning to climate change adaptation, for most

\footnotetext{
${ }^{10}$ For any search term, Google Trends provides a list of common related search terms. The most common skepticspecific search term was global warming hoax, but this term is more than 26 times less common than global warming. In addition, search volume is too low for the time series data of global warming hoax to be released for the vast majority of media markets. Even when a time series is available, there is typically only a single spike in search activity surrounded by zeros. However, a search for global warming can lead to skeptic websites. In addition to Wikipedia, EPA, and Scientific American entries on global warming, there are news stories from both sides of the debate and one popular denier website (globalwarming.org). A search for climate change tends not to lead to skeptic sites.
} 
intents and purposes it is moot whether or not someone believes in climate change if they are making forward-looking adaptation decisions with respect to droughts and floods.

As an additional robustness check on the data and methods, Column 4 presents results for the effect of weather fluctuations on weather GSI. In brief, the results generally show that bad weather (increases in average precipitation, increases in extreme precipitation, and cool temperatures in summer) cause people to search for weather. Intuitively, people are most dependent on weather when planning an outdoor activity, and thus adverse weather is expected to cause more searches. Thus, the results do seem consistent with expectations, and add further confidence to the research design.

\subsection{Heterogeneity in climate change related search behavior}

Table 2 presents results from estimates of the effect of weather fluctuations on global warming + climate change GSI using a variation of Equation (1) in which each weather variable is interacted with the media market's share of Democratic votes in the 2008 presidential election and the share of people with a college degree. The correlation between share Democrat and share college is 0.35, and thus it is preferred to include both sets of interactions to avoid incorrect inference. All three columns in Table 2 come from a single regression. Column 1 gives coefficient estimates on the level of each variable. Columns 2 and 3 give coefficient estimates for each variable interacted with share Democrat and share college, respectively. Both Democrat and college are de-meaned, or centered, which makes the main effects in the first column of Table 2 look very similar to the coefficients in Table 1. Thus, the interesting results come from Columns 2 and 3, which indicate if the relationship between weather fluctuations and GSI varies as cities become more or less Democratic or more or less educated.

The results show many statistically significant coefficients in Columns 2 and 3, suggesting that cities at different ends of the political or educational spectrum are responding differently to weather fluctuations. For average temperature, all coefficients in Columns 2 and 3 are positive and many are statistically significant, which suggests that increases in average temperature cause relatively more information seeking behavior in Democratic leaning or welleducated cities than in Republican leaning or less educated cities. In the case of summer, increases in heat cause GSI to increase in Democratic leaning or well-educated cities and decrease in Republican leaning or less educated cities. However, in the case of winter, all but the 
most Democratic and well-educated cities show decreases in GSI as temperatures increase. Turning to extreme heat, we see a similar but opposite pattern. The main effect of extreme heat is positive, and the coefficient on the interaction with education is negative (the coefficient on the interaction with ideology is also negative but insignificant). This result suggests that increases in extreme heat cause GSI to increase more in less educated cities, and the effect declines to negative for the most well educated cities. Further, the level and education interaction coefficients for heat streaks have the opposite sign, indicating that the effect of extreme heat on GSI decays with persistence for less educated cities, but becomes heightened for more educated cities. Lastly, looking at extreme cold, the coefficient on the interaction with share Democrat is positive suggesting that decreases in the number of cold days causes GSI to increase in Republican leaning cities and decrease in Democratic leaning cities.

To improve understanding of these difficult to interpret results, Figure 1 graphically illustrates the results of Table 2. The figure presents changes in GSI due to increases in average summer temperature, increases in extreme heat, and the net change for four representative cities. Across all cities, there is an average increase of 0.42 extreme heat days associated with an increase in average summer temperature of $1^{\circ} \mathrm{F}$. So the marginal changes in summer temperature used to create the figure are a $1^{\circ} \mathrm{F}$ increase in average temperature a 0.42 day increase of extreme heat. The four cities are chosen to represent the full spectrum of political ideology and educational attainment. Salt Lake City, UT and San Francisco, CA have a high percentage of college graduates (25.2\% and 32.4\%, respectively) and Knoxville, TN and Harlingen, TX have a low percentage of college graduates (15.6\% and 10.3\%, respectively). Salt Lake City, UT and Knoxville, TN have few Democratic voters (34.3\% and 32.4\%, respectively) and San Francisco, CA and Harlingen, TX have many Democratic voters (75.3\% and 68.6\%, respectively). In response to increases in average temperature, only San Francisco shows increases in GSI, cities with less education and less Democratic voters show decreases in GSI. This trend is reversed for responses to extreme heat with less Democratic and especially less educated areas showing increases in GSI. For the combined effect, Figure 1 suggests that areas with more Democratic voters are searching more when temperatures increase. However, this is for the normal combination of increases in average and extreme heat - different combinations of average and extreme heat may produce different orderings. Specifically, areas with a less educated population or fewer Democratic voters increase GSI substantially in the case of increases in extreme heat. 
The results of Table 2 and Figure 1 add richness to those presented in Table 1. This suite of results suggests that more Republican and less educated areas increase GSI in response to changes in extreme temperatures consistent with climate change, whereas more Democratic and well educated areas increase GSI in response to changes in average temperatures consistent with climate change. For all types of cities, there exists some weather event that increases engagement with climate change and is consistent with predicted changes. This could indicate that different types of people experience weather differently or have different perceptions about what type of weather defines climate change. ${ }^{11}$

\section{ConClusion}

Prior research has found a strong link between personal experiences of local weather and attitudes towards climate change (Akerlof et al. 2013, Egan and Mullin 2012, Hamilton and Stampone 2013, Zaval et al. 2014). This paper extends this vein of research to assess the extent to which local weather fluctuations cause individuals to seek information about climate change. My approach is distinctly revealed preference, which mitigates attribute substation and posturing biases that may affect the survey results. The results suggest that weather fluctuations do have an impact on climate change related search behavior, however not always in ways that are consistent with the impacts of climate change. While some of the counterintuitive results are magnified when heterogeneity by political ideology and educational attainment in responsiveness is modeled, the results also indicate that cities in all parts of the political and educational spectrum have triggers that elicit increased information seeking and are consistent with climate change. Some may see this as an encouraging result given continued political gridlock and prior research that has shown intransigence of opinions among some groups.

While this paper has advanced the understanding of climate change engagement through revealed preference data, it would be a major advancement to go one step further and understand the after-effects of information search. Future research should seek to assess how the process of acquiring knowledge matters for shaping opinion and policy support. Further, does active engagement lead to tangible actions towards mitigation or adaptation? For example, Jacobsen

\footnotetext{
${ }^{11}$ Given the uneven geographical distribution of political ideology and educational attainment in the United States, the results in Table 2 could be attributable to people of different climates responding differently to weather fluctuations. To examine this possibility, I also estimated a variation of Equation (1) in which the weather variables were interacted with indicator variables for climate terciles (defined by annual average temperature over the past 15 years). Results suggest few differences between climate zones.
} 
(2011) showed that exposure to climate change information can lead to an increase in voluntary carbon mitigation, even when people self-select into receiving information. Future research could examine if self-directed Google searches have a similar effect. On the adaptation side, future research could examine how information acquisition affects decisions about energy efficiency choices or flood protection or a host of smart adaptation strategies.

\section{REFERENCES}

Akerlof, K., Maibach, E.W., Fitzgerald, D., Cedeno, A.Y., \& Neuman, A. (2013). Do people 'personally experience' global warming, and if so how, and does it matter? Global Environmental Change, 23, 81-91.

Cavanaugh, P., Lang, C., Li, X., Miao, H., and Ryder, J. (2014). Searching for the determinants of climate change interest. University of Rhode Island Working Paper.

Choi, H., \& Varian, H. (2012). Predicting the present with Google Trends. The Economic Record, 88, 2-9.

Deschênes, O., Greenstone M., and Guryan, J. (2009). Climate Change and Birth Weight. The American Economic Review, 99(2): 211-17.

Egan, P.J., \& Mullin, M. (2012). Turning personal experience into political attitudes: the effect of local weather on Americans' perceptions about global warming. The Journal of Politics, 73(3), 796-809.

Gentzkow, M. and Shapiro, J.M. (2008). Introduction of Television to the United States Media Market, 1946-1960. ICPSR22720-v1. Chicago, IL: University of Chicago/Ann Arbor, MI: Inter-university Consortium for Political and Social Research [distributors], 2008-09-30. doi:10.3886/ICPSR22720.v1

Ginsberg, J., Mohebbi, M.H., Patel, R.S., Brammer, L., Smolinski, M.S., \& Brilliant, L. (2009). Detecting influenza epidemics using search engine query data. Nature, 457, 1012-14.

Goebbert, K., Jenkins-Smith, H.C., Klockow, K., Nowlin, M.C., \& Silva, C.L. (2012). Weather, climate, and worldviews: the sources and consequences of public perceptions of climate change in local weather patterns. Weather, Climate, and Society 4(2), 132-44.

Hamilton, L. and Lemcke-Stampone, M. (2013). Arctic Warming and Your Weather: Public Belief in the Connection. International Journal of Climatology, n/a.

Hamilton, L. and Stampone, M. (2013). Blowin' in the Wind: Short-Term Weather and Belief in Anthropogenic Climate Change. Weather, Climate, and Society, 5(2): 112-19.

Howe, P. and Leiserowitz, A.. (2013). Who Remembers a Hot Summer or a Cold Winter? The Asymmetric Effect of Beliefs about Global Warming on Perceptions of Local Climate Conditions in the U.S. Global Environmental Change, 23(6): 1488-1500.

IPCC, 2013: Summary for Policymakers. In: Climate Change 2013: The Physical Science Basis. Contribution of Working Group I to the Fifth Assessment Report of the Intergovernmental 
Panel on Climate Change [Stocker, T.F., D. Qin, G.-K. Plattner, M. Tignor, S. K. Allen, J. Boschung, A. Nauels, Y. Xia, V. Bex and P.M. Midgley (eds.)]. Cambridge University Press, Cambridge, United Kingdom and New York, NY, USA.

Jacobsen, G.D. (2011). The Al Gore effect: An Inconvenient Truth and voluntary carbon offsets. Journal of Environmental Economics and Management, 61, 67-78.

Kahn, M.E., \& Kotchen, M.J. (2011). Business cycle effects on concern about climate change: the chilling effect of recession. Climate Change Economics, 2(3), 257-73.

Maibach, E., Roser-Renouf, C., and Leiserowitz, A. (2009) Global Warming's Six Americas 2009: An Audience Segmentation Analysis.

Shanahan, J. and Good, J. (2000). Heat and Hot Air: Influence of Local Temperature on Journalists’ Coverage of Global Warming. Public Understanding of Science, 9(3): 285-95.

Stephens-Davidowitz, S. (2013). The effects of racial animus on a black presidential candidate: using Google search data to find what surveys miss. Harvard University Working Paper.

Zaval, L., Keenan, E., Johnson, E., and Weber, E. (2014). How Warm Days Increase Belief in Global Warming. Nature Climate Change, 4(2): 143-47. 


\section{FIGURES AND TABLES}

Table 1: Impact of weather fluctuations on Google Search Index (GSI)

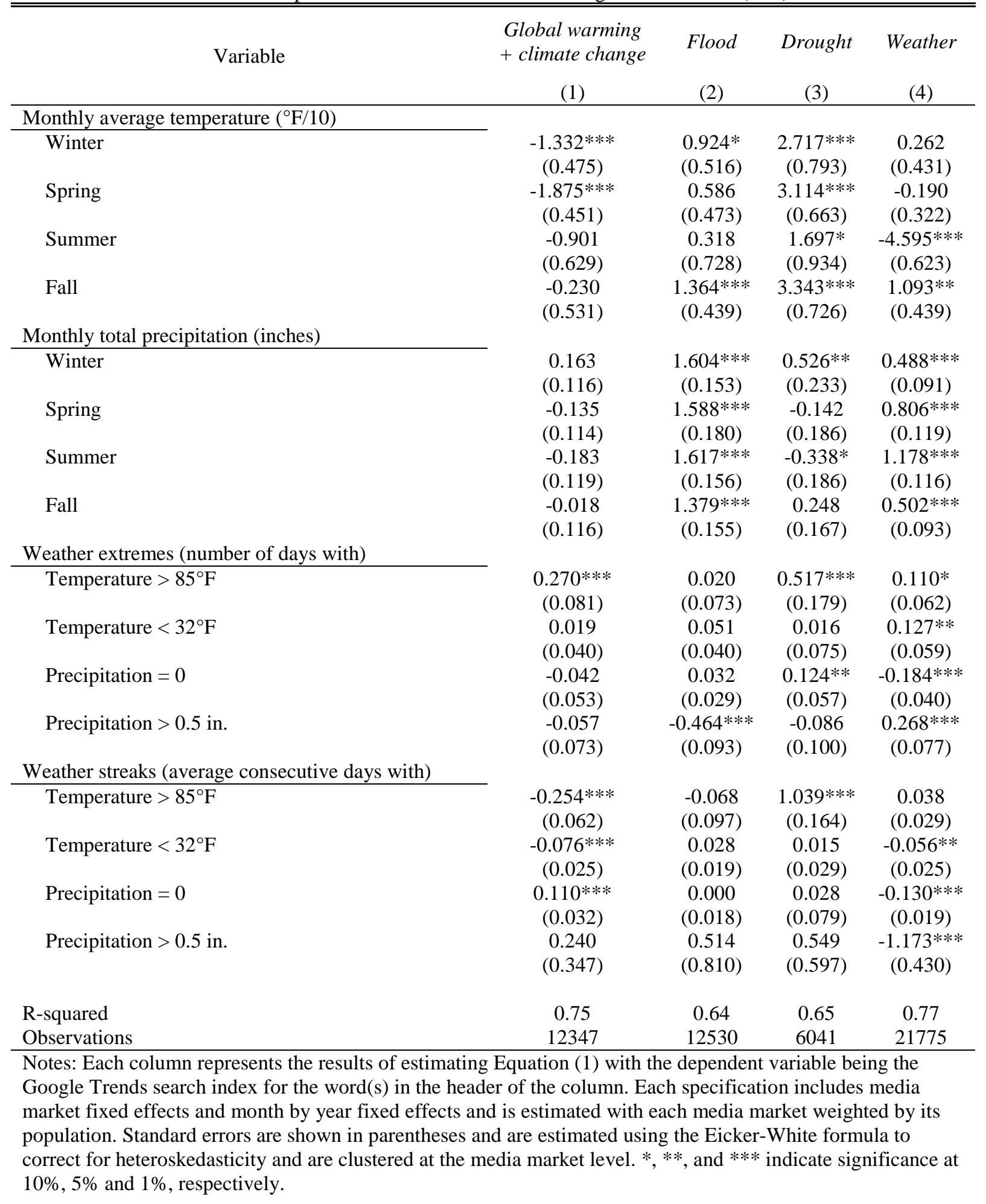


Table 2: Heterogeneous impacts of weather fluctuations on climate change related search behavior

\begin{tabular}{|c|c|c|c|}
\hline \multirow{3}{*}{ Variable } & \multicolumn{3}{|c|}{$\begin{array}{r}\text { Dep. Var. = global warming + climate change GSI } \\
\text { (All one regression) }\end{array}$} \\
\hline & Main effect & $\begin{array}{l}\text { Interacted with } \\
\text { Democrat vote share } \\
\text { (centered) }\end{array}$ & $\begin{array}{c}\text { Interacted with } \\
\text { share with college } \\
\text { degree } \\
\text { (centered) }\end{array}$ \\
\hline & (1) & (2) & (3) \\
\hline \multicolumn{4}{|c|}{ Monthly average temperature $\left({ }^{\circ} \mathrm{F} / 10\right)$} \\
\hline Winter & $\begin{array}{c}-1.115^{* *} \\
(0.441)\end{array}$ & $\begin{array}{c}0.088 * * * \\
(0.026)\end{array}$ & $\begin{array}{l}0.088^{*} \\
(0.046)\end{array}$ \\
\hline Spring & $\begin{array}{c}-1.231 * * * \\
(0.412)\end{array}$ & $\begin{array}{c}0.071^{* * *} \\
(0.020)\end{array}$ & $\begin{array}{c}0.065 \\
(0.041)\end{array}$ \\
\hline Summer & $\begin{array}{l}-0.087 \\
(0.593)\end{array}$ & $\begin{array}{c}0.049 * * * \\
(0.018)\end{array}$ & $\begin{array}{c}0.094 * * \\
(0.039)\end{array}$ \\
\hline Fall & $\begin{array}{c}0.037 \\
(0.479)\end{array}$ & $\begin{array}{l}0.035^{*} \\
(0.019)\end{array}$ & $\begin{array}{c}0.059 \\
(0.037)\end{array}$ \\
\hline \multicolumn{4}{|c|}{ Monthly total precipitation (inches) } \\
\hline Winter & $\begin{array}{c}0.129 \\
(0.132)\end{array}$ & $\begin{array}{c}-0.034^{* *} \\
(0.016)\end{array}$ & $\begin{array}{c}0.065^{* *} \\
(0.030)\end{array}$ \\
\hline Spring & $\begin{array}{c}-0.092 \\
(0.125)\end{array}$ & $\begin{array}{l}-0.005 \\
(0.014)\end{array}$ & $\begin{array}{c}0.038 \\
(0.029)\end{array}$ \\
\hline Summer & $\begin{array}{l}-0.113 \\
(0.120)\end{array}$ & $\begin{array}{l}-0.015 \\
(0.012)\end{array}$ & $\begin{array}{c}0.037 \\
(0.035)\end{array}$ \\
\hline Fall & $\begin{array}{c}-0.058 \\
(0.104)\end{array}$ & $\begin{array}{c}-0.003 \\
(0.011)\end{array}$ & $\begin{array}{l}0.048^{*} \\
(0.025)\end{array}$ \\
\hline \multicolumn{4}{|c|}{ Weather extremes (number of days with) } \\
\hline Temperature $>85^{\circ} \mathrm{F}$ & $\begin{array}{c}0.234 * * * \\
(0.074)\end{array}$ & $\begin{array}{l}-0.007 \\
(0.006)\end{array}$ & $\begin{array}{c}-0.030 * * \\
(0.013)\end{array}$ \\
\hline Temperature $<32^{\circ} \mathrm{F}$ & $\begin{array}{c}0.042 \\
(0.040)\end{array}$ & $\begin{array}{c}0.007 * * \\
(0.004)\end{array}$ & $\begin{array}{c}0.004 \\
(0.008)\end{array}$ \\
\hline Precipitation $=0$ & $\begin{array}{c}-0.046 \\
(0.043)\end{array}$ & $\begin{array}{c}0.002 \\
(0.005)\end{array}$ & $\begin{array}{c}0.004 \\
(0.010)\end{array}$ \\
\hline Precipitation > 0.5 in. & $\begin{array}{c}0.042 \\
(0.080)\end{array}$ & $\begin{array}{c}0.001 \\
(0.009)\end{array}$ & $\begin{array}{c}-0.047 * * \\
(0.020)\end{array}$ \\
\hline \multicolumn{4}{|c|}{ Weather streaks (average consecutive days with) } \\
\hline Temperature $>85^{\circ} \mathrm{F}$ & $\begin{array}{c}-0.185^{* *} \\
(0.073)\end{array}$ & $\begin{array}{c}0.009 \\
(0.006)\end{array}$ & $\begin{array}{l}0.024^{*} \\
(0.014)\end{array}$ \\
\hline Temperature $<32^{\circ} \mathrm{F}$ & $\begin{array}{c}-0.094^{* * *} \\
(0.031)\end{array}$ & $\begin{array}{c}-0.006 * * \\
(0.003)\end{array}$ & $\begin{array}{c}0.006 \\
(0.004)\end{array}$ \\
\hline Precipitation $=0$ & $\begin{array}{c}0.054 \\
(0.039)\end{array}$ & $\begin{array}{c}0.002 \\
(0.004)\end{array}$ & $\begin{array}{l}-0.001 \\
(0.006)\end{array}$ \\
\hline Precipitation > 0.5 in. & $\begin{array}{c}-0.842 \\
(0.685)\end{array}$ & $\begin{array}{c}0.023 \\
(0.061)\end{array}$ & $\begin{array}{l}0.209 * \\
(0.112)\end{array}$ \\
\hline
\end{tabular}

Notes: All coefficients come from a single regression in which all of the weather variables from Equation (1) are interacted with the share of votes going to the Democratic candidate in the 2008 presidential election (Column 2) and the share of the over 25 population with a college degree (Column 3). Both Democrat share and college degree share are centered, or de-meaned, such that the value takes on the deviation from nationwide average. The dependent variable in the regression is the Google Trends search index for global warming + climate change. The specification includes media market fixed effects and month by year fixed effects and is estimated with each media market weighted by its population. The regression has 12,347 observations and an R-squared 0.76 . Standard errors are shown in parentheses and are estimated using the Eicker-White formula to correct for heteroskedasticity and are clustered at the media market level. *, **, and *** indicate significance at $10 \%, 5 \%$ and $1 \%$, respectively. 
Figure 1: Illustration of heterogeneous changes in GSI due to increases in average and extreme heat

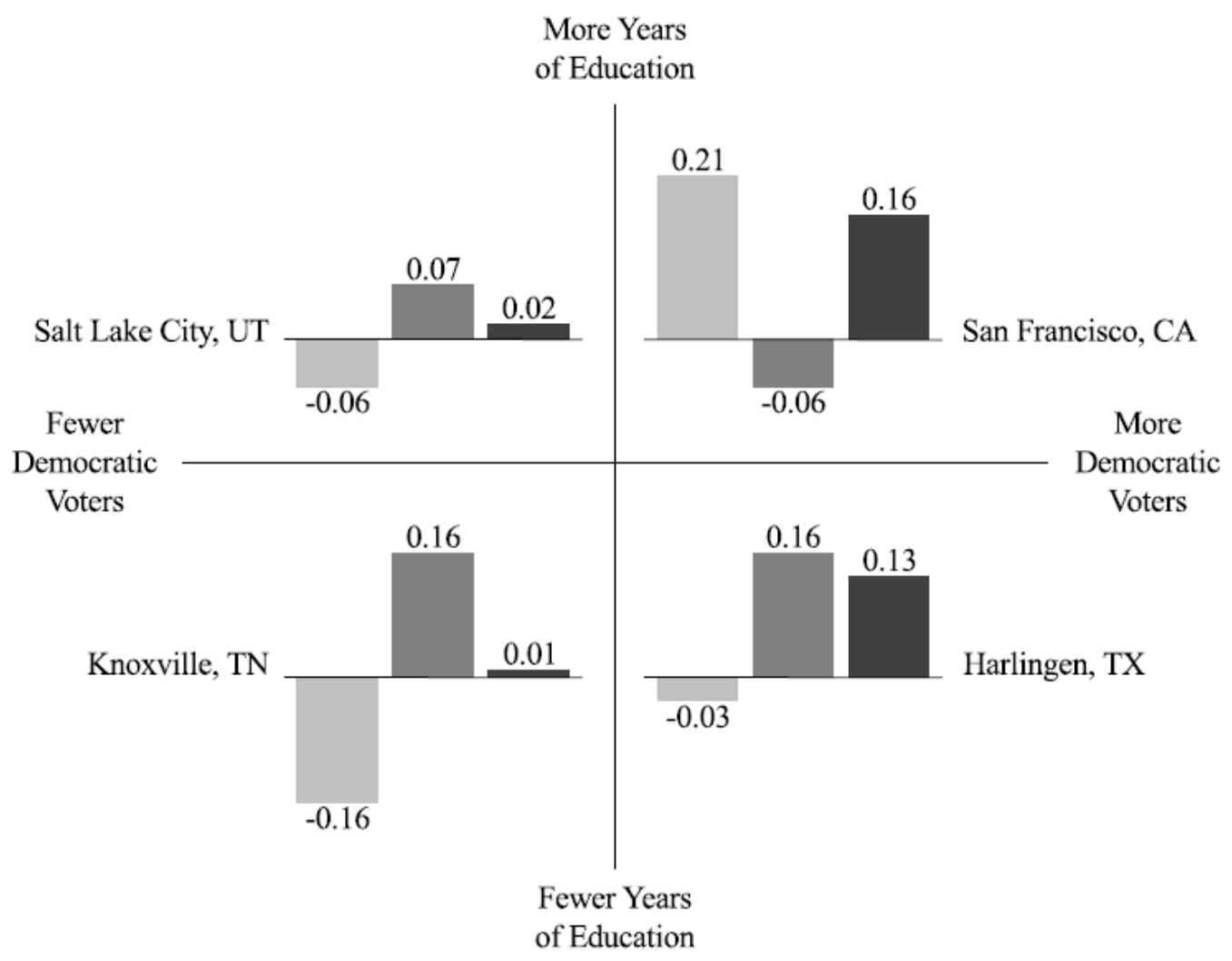

Increase in average heat Increase in extreme heat

Combined effect

Notes: GSI responses are calculated using coefficients from Table 2 and the Democratic vote share and share of adults with college degree for each city for a $1^{\circ} \mathrm{F}$ increase in average summer temperature and a 0.42 day increase in extreme heat. Across all cities and time, there is an average increase of 0.42 extreme heat days associated with an increase in average summer temperature of $1^{\circ} \mathrm{F}$. 